\title{
ANALISIS KESESUAIAN LAHAN AGROFORESTRI BERBASIS SISTEM INFORMASI GEOGRAFI (SIG) DI DESA SINDULANG KABUPATEN SUMEDANG
}

\author{
Analyze of Agroforestry Land Suitability Based on Geographic Information \\ System in Sindulang Village, Sumedang Regency \\ Prasetyo Widodo $^{1)}$, Rian Susila ${ }^{2)}$, Wasmanudin ${ }^{3)}$ \\ 1) Staf Pengajar Fakultas Kehutanan Universitas Winaya Mukti, \\ $\left.{ }^{2}\right)$ Staf Pengajar Fakultas Kehutanan Universitas Winaya Mukti, \\ 3) Mahasiswa Fakultas Kehutanan Universitas Winaya Mukti, Sumedang \\ Jl Raya Bandung-Sumedang km 29 Tanjungsari, Sumedang 45362
}

\section{Diterima 13 September 2018/Disetujui 10 Oktober 2018}

\begin{abstract}
The condition of social, economic, and culture of forest community has effect to forest condition. Desa Sindulang is one of village that community forest in Taman Buru Masigit Karembi that has majority of farmer and low economic condition. But commodity planting is carried out without an evaluation of the land to determine the level of suitability of the land with the commodities planted. The method by overlay Land Mapping Unit with society land use then analyze of matching suitability land. The results of evaluation divided in 3 units, are : 1) unit I which have land suitability class values with forestry commodities such as Suren (Toona sureni) and Coffee (Coffea Arabica) while agricultural commodities such as Broccoli (Brassica oleracea), Chili (Capsicum annum), Banana (Musa acuminate) and Cabbage (Brasica oleracea). 2) Units II which have land suitability class values with forestry commodities such as Suren (Toona sureni) and Coffee (Coffea arabica) while agricultural commodities such as Tomato (Solanum lycopersicum). 3) Units III which have land suitability class values with forestry commodities such as Suren (Toona sureni), Africa (Maesopsis eminii) and Coffee (Coffea arabica) while agricultural commodities such as Tomato (Solanum lycopersicum), Eggplant (Solanum melongena) Broccoli (Brassica oleracea), Chili (Capsicum annum), Cabbage (Brasica oleracea) and Pineapple (Ananas Comosus).
\end{abstract}

Keywords : Agroforestry, Land suitability, Sindulang Village 


\section{PENDAHULUAN}

Taman Buru Masigit kareumbi merupakan hutan konservasi yang berfungsi sebagai pelestari alam dan taman wisata alam. Taman Buru Masigit Kareumbi berfungsi juga sebagai penyangga kehidupan karena merupakan bagian dari hulu DAS Citarum, dimana wilayah hulu DAS memiliki peranan esensial terhadap perlidungan kawasan di bawahnya. DAS Citarum merupakan daerah aliran sungai terbersar yang berada di Jawa Barat, (BPDAS Citarum-Ciliwung 2010).

Secara administrasi Taman Buru Masigit Kareumbi berada dalam tiga Kabupaten yaitu Kabupaten Garut, Bandung, dan Sumedang. Di Kabupaten Sumedang ada 8 kecamatan dan 37 Desa desa yang berbatasan langsung dengan Taman Buru Masigit Kareumbi diantaranya yaitu Desa Tegal Manggung, Cimanggung, Cinanggerang, Sindang Pakuaon dan Desa Sindulang yang berada di Kemacatan Cimanggung.

Kondisi, sosial, ekonomi maupun budaya desa sekitar hutan sangat berpengaruh terhadap kondisi hutan. Desa Sindulang merupakan salah satu desa yang berbatasan dengan Taman Buru Masigit Kareumbi sebagian besar (85\%) masyarakat hanya menempuh pendidikan hingga tingkat Sekolah Dasar (SD), secara ekonomi tingkat kesejahtraan masyarakat Desa Sindulang masih berada golongan rendah terutama pada masyarakat yang berprofesi sebagai petani dengan luas lahan garapan kurang dari 0,25 Ha.

Selama ini pemilihan komoditas komoditas tanaman yang dibudidayakan masyarakat di Desa Sindulang masih dilakukan secara sederhana tanpa dilakukan evaluasi lahan untuk mengetahui tingkat kesesuian lahan dengan komoditas yang ditanam, sehingga dapat menyebabkan kecenderungan untuk memperluas lahan garapan dan tidak menutup kemungkinan dapat merambah ke dalam kawasan konservasi Taman Buru Masigit Kareumbi. Oleh karena itu, dalam rangka optimalisasi lahan diperlukan strategi dan cara yang tepat supaya tanaman dapat tumbuh dan berkembang secara optimal untuk menghasikan produktifitas yang tinggi. Dalam rangka menunjang hal tersebut perlu diketahui potensi dan kualitas lahan melalui kegiatan evaluasi kesesuaian lahan (Harjowigeni dan Widiatmaka 2001). Kegiatan evaluasi lahan meliputi proses perumusan secara spasial penggunaan lahan dengan mempertimbangkan aspek ekologi, ekonomi dan sosial, yaitu pemilihan tanaman agroforestri yang bernilai ekonomis sesuai dengan kemampuan lahan di sekitar kawasan yang berbatasan langsung dengan Taman Buru Masigit Kareumbi. 
Berdasarkan permasalahan di atas peneliti tertarik untuk melakukan Analisis Kesesuain Agroforestri dengan Menggunakan Sistem Informasi Geografi (SIG) Di Desa Sindulang Kabupaten Sumedang, sehingga diharapkan dapat memberikan solusi dalam optimalisasi lahan agroforestri sebagai upaya untuk meningkatkan kesejahteraan masyarakat di sekitar kawasan Taman Buru Masigit Kareumbi.

\title{
METODOLOGI PENELITIAN
}

\section{Waktu dan Tempat}

Penelitian dilaksanakan pada bulan Juli sampai dengan Oktober tahun 2017 di Desa Sindulang Kecamatan Kabupaten Sumedang.

\begin{abstract}
Alat dan Bahan
Alat yang digunakan dalam penelitian ini adalah perangkat lunak (software) berupa ArcGIS versi 10.3, laptop, Global Position System (GPS), kamera digital, sekop/cangkul, kantong plastik (plastik sampel), ember, roll meter, dan alat tulis. Bahan yang digunakan dalam penelitian ini berupa Peta topografi (lereng, ketinggian tempat), Peta tanah (Jenis tanah) Peta Iklim (curah hujan), Peta Tutupan Lahan (land use), dan Peta administrasi.
\end{abstract}

\section{Metode Pengumpulan Data}

\section{Persiapan Penelitian}

Tahap persiapan meliputi pengumpulan data yang berkaitan dengan penelitian yang berupa peta topografi (lereng), peta tanah (jenis tanah) peta iklim (curah hujan), peta tutupan lahan (land use), dan peta administrasi dilakukan dengan overlay peta admistrasi Desa Sindulang dengan peta tutupan lahan serta penelaahan peta lokasi dengan cara mendelinasi (mendigitasi) pada bagian perladangan atau lahan agroforestri yang berbatasan langsung dengan kawasan Taman Buru Masigit Karembi.

\section{Penentuan Satuan Lahan /Land Mapping Unit (LMU)}

Penentuan Land Mapping Unit ( $L M U$ ) dilakukan atas dasar bentuk biofisik. Tahapan yang dilakukan dalam penentuan Land Mapping Unit sebagai berikut:

1. Daerah yang dideliniasi merupakan areal Ladang/agroforestri yang berbatasan langsung dengan Taman Buru Masigit Kareumbi

2. Kemudian menumpang tindihkan (overlay) beberapa objek lahan, objek 
penelitian satuan lahan parameter biofisik yang dianalisis melalaui Arcgis, Parameter yang dipilih dalam penelitian ini adalah kelerengan, jenis tanah, dan curah hujan. Bila salah satu parameter berubah maka satuan lahan akan berubah pula. Peta satuan lahan yang dihasilkan dapat digunakan sebagai peta acuan dasar dalam pembuatan plot invetarisasi tanaman agroforestri, dan pengambilan contoh sampel tanah.

Hasil dari acuan peta satuan lahan (land mapping unit) dapat diklasifikasikan dalam Tabel 1. sebagai berikut:

Tabel 1. Klasifikasi Satuan Lahan (Land Mapping Unit)

\begin{tabular}{llllccc}
\hline No & $\begin{array}{c}\text { Satuan } \\
\text { Lahan } \\
\text { (LMU) }\end{array}$ & $\begin{array}{c}\text { Jenis } \\
\text { Tanah }\end{array}$ & kelerengan & $\begin{array}{c}\text { Curah } \\
\text { Hujan } \\
\text { (mm/tahun) }\end{array}$ & $\begin{array}{c}\text { Ketinggian } \\
\text { Tempat } \\
\text { mdpl }\end{array}$ & $\begin{array}{c}\text { Luas } \\
\text { (ha) }\end{array}$ \\
\hline 1 & I & Latosol & $<8 \%$ & $2000-2500$ & $1162.5-1171.5$ & 1.7 \\
2 & II & Latosol & $8 \%-15 \%$ & $2500-3000$ & $1172.5-1212.5$ & 2.89 \\
3 & II & Latosol & $8 \%-15 \%$ & $2000-2500$ & $1162.5-1237.5$ & 20.8 \\
4 & IV & Latosol & $16 \%-25 \%$ & $2000-2500$ & $1175-1262.5$ & 8.21 \\
\hline
\end{tabular}

\section{Penentuan Pengambilan Sampling}

Penentuan dan pengambilan sample dilakukan dengan metode purpsive sampling berdasarkan pertimbanagan berikut:

a. Keterwakilan (Representativeness), lokasi penelitian mememiliki biofisik lahan yang berbeda terbagi dalam empat land mapping unit (LMU). Maka tiap $L M U$ pada areal penelitian diambil sampel untuk memenuhi kiteria keterwakilan dari masing-masing land mapping unit yang ditentukan pada peta pengambilan sampling. Dapat dilihat pada gambar 5 .

b. Kepraktisan (Effiency), penempatan dan penggunaan intensitas sampling untuk pengambilan contoh sampling dengan mengupayakan tingkat ketelitian yang dapat dipertanggung jawabkan, dengan pengorbanan waktu, tenaga dan biaya minimal. Dapat dilihat pada tabel 3 dan gambar 5.

c. Ketelitian (Accuracy) sedapat mungkin tidak melampaui batas-batas tertentu yang ditetepkan, dimana hal tersebut dipengaruhi oleh tingkat keragaman populasi dan jumlah atau intensitas sampling. Maka dalam penelitian ini intensitas sampling yang digunakan untuk inventarisasi vegetasi penyusun agroforestri ditentukan sebesar $1 \%$ dengan bentuk plot persegi empat dengan berukuran 20 x 20 m, dengan luas lahan 33,6 ha, intensitas sampling tersebut berdasakan (Permenhut No. P.67/Menhut-II/2006 Tahun 2006 tentang Kriteria dan Standar Inventarisasi Hutan) dimana untuk Inventarisasi Hutan 
Rakyat intensitas sampling yang digunakan minimal adalah $0.5 \%$. Sehingga didapat jumlah plot pada masing masing ( $L M U)$. Dapat dilihat pada tabel 3.

Sedangkan Pengambilan sampel Contoh tanah secara komposit berdasakan Land Mapping Unit, satu sampel contoh tanah mewakili 5 ha (BPPP 2015), maka masing-masing luasan blok atau starata $L M U$ dibagai 5, dapat dilihat pada Tabel 2 sebagai berikut:

Tabel 2. Jumlah Plot berdasarkan intensitas Sampling dan Komposit Sampel

\begin{tabular}{ccccc}
\hline \multirow{2}{*}{$\begin{array}{c}\text { Satuan Lahan } \\
(\text { LMU) }\end{array}$} & Luas & \multicolumn{2}{c}{ Jumlah Plot } & $\begin{array}{c}\text { Jumlah } \\
\text { Sampel } \\
\text { Tanah }\end{array}$ \\
\cline { 3 - 4 } & (ha) & Vegetasi & Tanah & $\begin{array}{c}\text { Tann } \\
\text { I }\end{array}$ \\
II & 1.7 & 1 & 1 & 1 \\
III & 2.89 & 1 & 5 & 1 \\
IV & 20.8 & 5 & 2 & 1 \\
\hline
\end{tabular}

Tanah

Setelah diperoleh jumlah masing-masing plot dalam satuan lahan (LMU) lalu dimasukan kedalam peta untuk memperoleh titik plot diasajiakan pada Gambar 1.

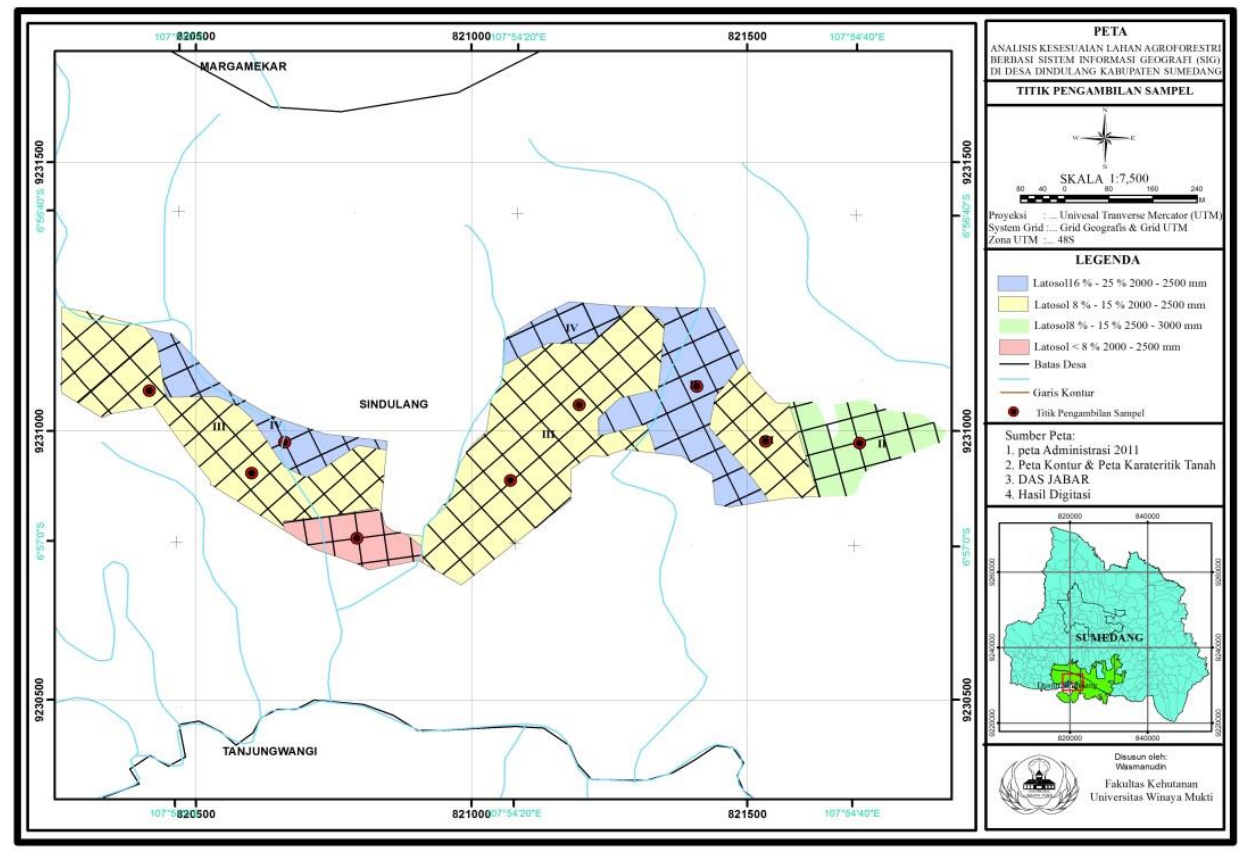

Gambar 1. Gambar titik masing-masing plot dalam Land Mapping Unit

Dari peta titik pengambilan sampel diperoleh koordinat pada masing masing satuan lahan $(L M U)$ dapat dilihat pada Tabel 3. Sebagai berikut: 
Tabel 3. Titik Koordinat Pengambilan Sampel Vegetasi dan Tanah

\begin{tabular}{cccccccc}
\hline \multirow{2}{*}{ No } & \multirow{2}{*}{$\begin{array}{c}\text { Nomor } \\
\text { Plot }\end{array}$} & \multicolumn{2}{c}{ Koordinat } & & \multirow{2}{*}{$\begin{array}{c}\text { Satuan } \\
\text { Lahan }\end{array}$} & & \multicolumn{2}{c}{ Pengambilan Sampel } \\
& & $\mathbf{X}$ & $\mathbf{L M U})$ & Vegetasi & Tanah \\
\hline 1 & 4 & 820801 & 9230803 & I & $\checkmark$ & $\checkmark$ \\
2 & 9 & 821680 & 9230963 & II & $\checkmark$ & $\checkmark$ \\
3 & 1 & 820398 & 9231123 & & $\checkmark$ & $\checkmark$ \\
4 & 2 & 820598 & 9230924 & & $\checkmark$ & $\checkmark$ \\
5 & 5 & 821037 & 9230885 & III & $\checkmark$ & $\checkmark$ \\
6 & 6 & 821156 & 9231044 & & $\checkmark$ & $\checkmark$ \\
7 & 8 & 821518 & 9231005 & & $\checkmark$ & $\checkmark$ \\
8 & 3 & 820681 & 9230969 & & $\checkmark$ & $\checkmark$ \\
9 & 7 & 821399 & 9231085 & IV & $\checkmark$ & $\checkmark$ \\
\hline
\end{tabular}

\section{Survei lapangan}

\section{Rancangan Pelaksanaan Penelitian}

Survei (observasi lapangan) ke areal yang sudah ditentukan perlu dilakukan guna melihat dan mengecek apakah gambaran daerah yang ada di peta sesuai dengan kondisi yang sesungguhnya di lapangan.

\section{Prosedur PengambilanData}

Kegiatan pada tahap ini berupa pengumpulan data primer yang meliputi keragaman spesies tanaman agroforestri dan syarat tumbuh tanaman, adapun tahapan inventarisasi tamaman agroforestri sebagai berikut:

1. Membuat 9 plot dengan ukuran $20 \times 20 \mathrm{~m}$ untuk tingkat pohon tanaman pertanian, $10 \times 10 \mathrm{~m}$ untuk tingkat tiang, 5 x 5 m untuk tingkat pancang, dan 2 x 2 m untuk tingkat semai. yang di alokasikan pada masing-mang satuan lahan yang sudah ditentukan pada peta pengambilan sampel atau plot.

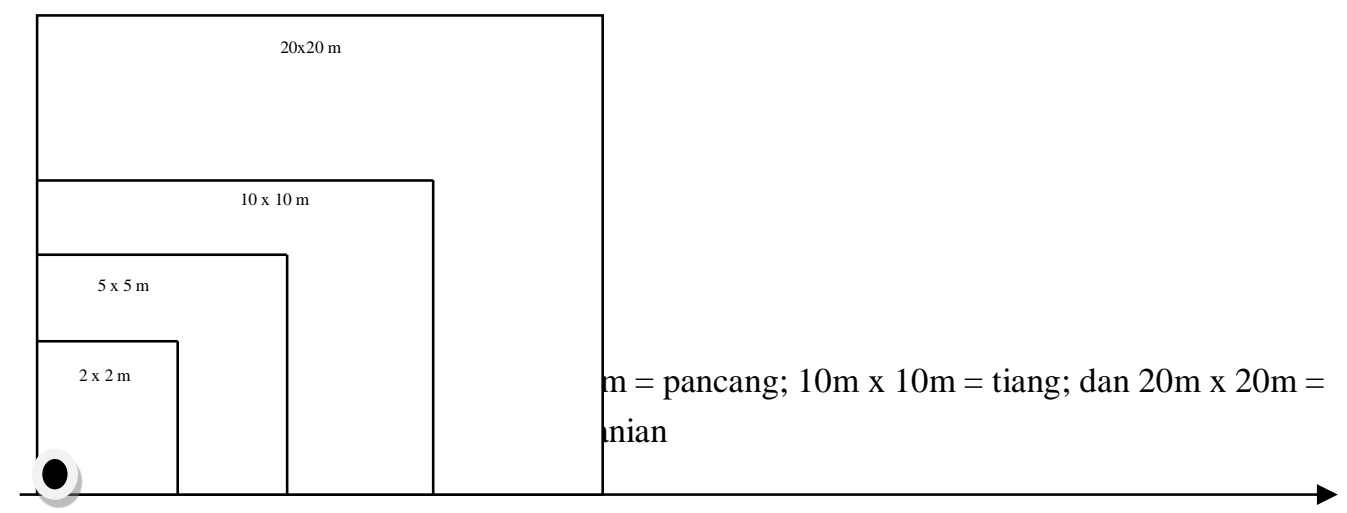

Gambar 2. Bentuk plot analisis vegetasi penyusun agroforestri. 
2. Mencatat species tanaman agroforestri yang berada dalam plot tersebut.

3. Studi pustaka mengenai syarat tumbuh tanaman agroforestri yang ada.

Kemudian tahap selanjutnya pengupulan data yang meliputi parameter biofisik yang dapat diukur di lapangan yaitu pengambilan sampel tanah untuk dianalisis di laboratorium. Langkah - langkah dalam pengambilan sampel tanah dapat diuraikan sebagai berikut (Yamani 2010):

1. Memilih lokasi untuk pengambilan sampel tanah (pada areal lahan agroforestri dengan lahan luas 33.6 ha ).

2. Menentukan tempat pengambilan sampel tanah berdasarkan pada peta satuan lahan (land mapping unit) dengan pengambilan contoh tanah dilakukan secara Purposive sampling.

3. Membersihkan permukaan tanah dari serasah, rumput atau tanaman penutup tanah lainnya

4. Mengambil sampel tanah pada lapisan olah tanah dengan kedalaman 0-20 cm, dengan pertimbangan bahwa unsur hara sebagian besar berada pada kedalaman ini dan di kompositkan berdasakan land mapping unit.

5. Sampel tanah yang telah diambil, kemudian dianalisis kandungan retensi hara ( $\mathrm{pH}, \mathrm{N}, \mathrm{P}, \mathrm{K})$ di Laboratorium.

\section{Tahap Pengolahan Data}

Skema analisis kesesuain lahan dalam bentuk bagan bagan dapat dilihat dalam gambar.

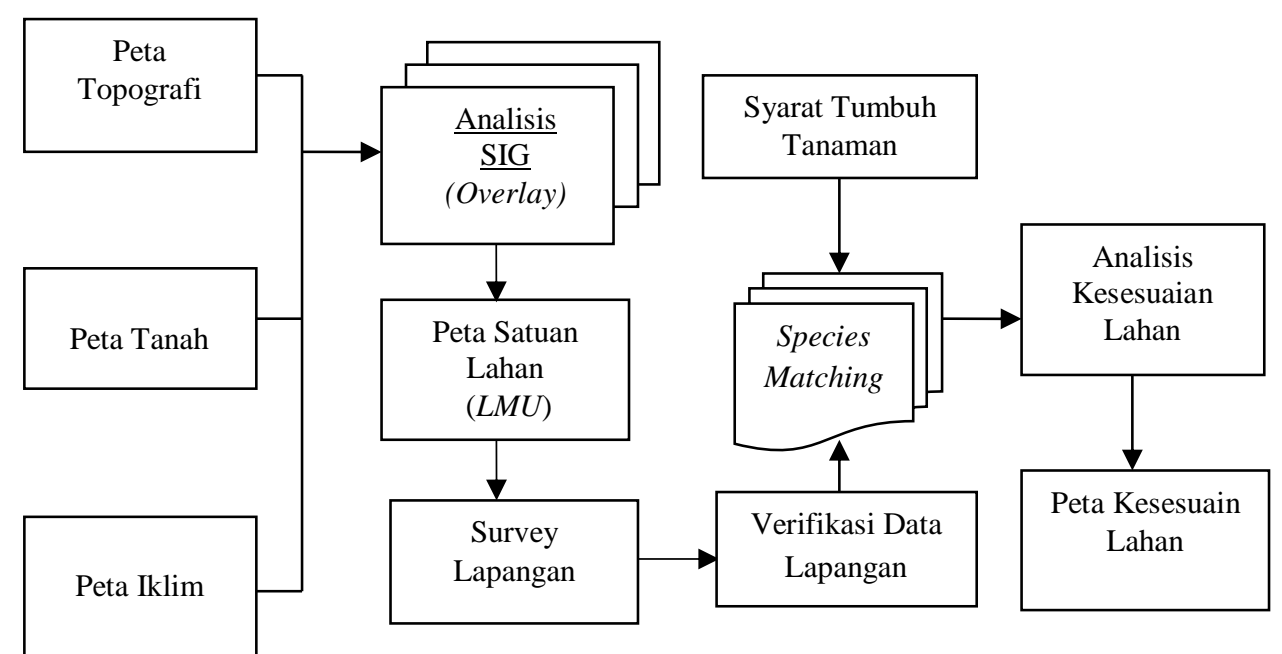

Gambar 3. Skema penelitian analisis kesesuaian lahan. 


\section{HASIL DAN PEMBAHASAN}

\section{Evaluasi Kesesuaian Lahan}

Evaluasi kesesuaian lahan dalam penelitian ini menggunakan parameter biofisik berupa jenis tanah, ketinggian tempat, curah hujan, kelerangan dan parameter kesuburan lahan berupa retensi hara $(\mathrm{pH}, \mathrm{N}, \mathrm{P}, \mathrm{K})$. Parameter tersebut dikelompokan menjadi dua faktor pembatas/penghambat yaitu faktor penghambat yang bisa diperbaiki/diubah dan faktor pembatas given/tidak bisa dipebaiki.

Faktor penghambat yang dapat diperbaiki yaitu berupa kesuburan lahan dan retensi hara berupa $(\mathrm{pH}, \mathrm{N}, \mathrm{P}, \mathrm{K})$ dengan penambahan bahan organik dan pengapuran serta kelerengan dapat diperbaiki dengan teknik konservasi tanah dan air. Faktor penghambat berupa Temperatur, curah hujan ketinggian tempat dan jenis tanah merupakan faktor penghambat yang tidak dapat diperbaiki karena merupakan faktor penghambat alam.

Kesesuaian lahan dapat dinilai secara aktual maupun potensial serta dijadikan dasar dalam penentuan indikator dan pengukur terpilih dalam penyusunan kesesuaian lahan yang selanjutnya dituangkan dalam bentuk data spasial. Hal ini sesuai dengan pernyataan Djaenudin et al (2000) bahwa masingmasing kesesuaian lahan dapat dinilai secara aktual maupun potensial. Kesesuaian lahan aktual adalah kesesuaian lahan yang dilakukan pada kondisi penggunaan lahan sekarang (present land use), tanpa adanya masukan untuk perbaikan, sedangkan kesesuaian lahan potensial adalah kesesuaian lahan yang dilakukan pada kondisi setelah diberikan masukan untuk perbaikan, seperti penambahan pupuk maupun perbaikan tergantung dari jenis faktor pembatasnya atau pengahambatnya.

Kemampuan lahan didasarkan pada empat satuan lahan dimana satuan lahan didefinisikan sebagai area homogen dalam berbagai parameter biofisik lahan (tanah, lereng, curah hujan) yang dapat diidentifikasikan langsung di lapangan. Oleh karena itu, satuan lahan yang sama (homogen) akan mencerminkan kesamaan potensi serta faktor pembatasnya dimanapun sistem lahan tersebut dijumpai. Kualitas dan karakteristik lahan dapat dilihat pada Tabel 4.

Evaluasi kesesuaian lahan dilakukan pada 29 jenis tanaman yang ada di kawasan agroforestri dengan proses matching antara pembatas permanen (temperatur, curah hujan, jenis tanah, dan ketinggian tempat) dengan kiteria syarat tumbuh tanaman pada masing-masing satuan lahan, sehingga diperkirakan tanaman dapat tumbuh optimal dan merekomendasikan tanaman yang memiliki kelas kesesuaian lahan S1 faktor pembatas permanen dan tidak memiliki kalas 
kesesuaian lahan $\mathrm{N}$ (Tidak Sesuai) faktor pembatas yang bisa dirubah. Karakteristik lahan masing-masing satuan lahan memiliki nilai faktor pembatas permanen dan bisa diubah berbeda maka rekomedasi tanaman pada msingmasing satuan lahan berbeda pula.

Tabel 4. Karakteristik dan Kualitas Lahan pada Masing-Masing Satuan Lahan

\begin{tabular}{cccccc}
\hline \multirow{2}{*}{ No } & $\begin{array}{c}\text { Karakteristik } \\
\text { Lahan }\end{array}$ & \multicolumn{4}{c}{ Satuan Lahan } \\
\cline { 3 - 6 } & & I & II & III & IV \\
\hline \multirow{2}{*}{1} & Temperatur & $20-27$ & $20-27$ & $20-27$ & $20-27$ \\
& rata-rata $\left({ }^{\circ} \mathrm{C}\right)$ & & & & \\
2 & Curah hujan & $2000-2500$ & $2500-3000$ & $2000-2500$ & $2000-2500$ \\
& (mm/tahun) & & $8-15$ & $8-15$ & $16-25$ \\
3 & Kelerengan $(\%)$ & $<8$ & Latosol & Latosol & Latosol \\
4 & Jenis tanah & Latosol & $1172.5-1212.5$ & $1162.5-1237.5$ & $1175-1262.5$ \\
5 & Ketinggian & $1162.5-1171.5$ & 5,16 & 4,56 & 4,04 \\
6 & pH tanah & 5,35 & 0,21 & 0,48 & 0,18 \\
7 & N-total & 0,30 & 57 & 281 & 38 \\
8 & $\mathrm{P}_{2} 0_{5}$ & 232 & 206,7 & 67,6 & 146 \\
9 & $\mathrm{~K}_{2} 0$ & 154,5 & & & \\
\hline
\end{tabular}

Sumber: Hasil Penelitian, 2017

\section{KESIMPULAN}

Berdasarkan evaluasi lahan dapat direkomendasikan tanaman memiliki nilai kelas kesesuain lahan S1 (sangat sesuai) dengan parameter biofisik permanen dan tidak memiliki kelas keseauaian $\mathrm{N}$ (tidak sesuai) pada faktor pembatas kesuburan lahan dan biofisik yang dapat diubah.

a. Satuan lahan I berupa Suren (Toona sureni) dan Kopi (Coffea arabica) Brokoli (Brassica oleracea), Cabai (Capsicum annum), Pisang (Musa acuminate) dan Kubis (Brasica oleracea), tanaman lain Afrika (Maesopsis eminii), Tomat (Solanum lycopersicum), Nanas (Ananas Comosus) dan Terung (Solanum melongena).

b. Satuan lahan II berupa tanaman Suren (Toona sureni) dan Kopi (Coffea arabica) tomat (Solanum lycopersicum) tanaman lain yang direkomendasikan adalah tanaman Afrika (Maesopsis eminii), Brokoli (Brassica oleracea), Cabai (Capsicum annum), Kubis (Brasica oleracea) dan Terung (Solanum melongena).

c. Satuan lahan III berupa Suren (Toona sureni), Afrika (Maesopsis eminii) dan Kopi (Coffea arabica) sedangkan komoditas pertanian berupa tanaman Tomat 
(Solanum lycopersicum), Terung (Solanum melongena) Brokoli (Brassica oleracea), Cabai (Capsicum annum), Kubis (Brasica oleracea) dan Nanas (Ananas Comosus).

d. Satuan lahan IV berupa Suren (Toona sureni), Afrika (Maesopsis eminii), Kopi (Coffea arabica) dan Pisang (Musa acuminate) tanaman lain yang direkomendasikan adalah tanaman Nanas (Ananas Comosus).

\section{DAFTAR PUSTAKA}

Arsyad, S. 2006. Konsevasi Tanah dan Air. IPB Press. Bogor.

BPDAS Citarum-Ciliwung. 2010. Rencana Pengelolaan DAS Terpadu Citarum

Hulu, Direktorat Jenderal Perhutanan Sosial dan Pengelolaan. Kementerian Kehutanan, Bogor.

Djaenudin D, Marwan H, Subagyo H, Mulyani A, dan Suharta N. 2000.

Kriteria Kesesuaian Lahan Untuk Komoditas Pertanian. Pusat Penelitian Tanah dan Agroklimat. Bogor.

Ellyanti A, Karim, dan H Basri. 2012. Analisis indikasi geografis kopi Arabika Gayo ditinjau dari rencana tata ruang wilayah kabupaten. Jurnal Agrista, 2, $46-61$.

Mahendra F. 2009. Sistem Agroforestry dan Aplikasinya. Graha Ilmu. Yogyakarta.

Maftuhah Ima. 2009. Pengaruh Berbagai Bahan Pembenah Tanah Terhadap Sifat Fisik Tanah Latosol Untuk Budidaya Tanaman Sayuran. Skripsi. Program

Studi Ilmu Tanah Departemen Ilmu Tanah Dan Sumberdaya Lahan Fakultas Pertanian Institut Pertanian Bogor.

Yamani Ahmad. 2010. Analisis Kadar Hara. Jurnal Hutan Tropis 11 (30): 37-46. 